Revista Universo Contábil, ISSN 1809-3337
Blumenau, v. 15, n. 2, p. 97-115, abr./jun., 2019

\title{
REAÇÃO DO MERCADO À OPINIÃO MODIFICADA DA AUDITORIA: VALOR DE MERCADO E PERCEPÇÃO DE RISCO
}

\section{MARKET REACTION TO THE AUDIT MODIFIED OPINION: MARKET VALUE AND RISK PERCEPTION}

\section{REACCIÓN DEL MERCADO A LA OPINIÓN MODIFICADA DE LA AUDITORÍA: VALOR DE MERCADO Y PERCEPCIÓN DE RIESGO}

Recebido em: 15/12/2018

Avaliado em: 19/07/2019

Reformulado em:24/08/2019

Aceito para publicação em: 06/11/2019

Publicado em: 30/11/2019

Editor Responsável: Moacir M. Rodrigues Junior

\author{
Denis Leite Carvalho ${ }^{1}$ \\ Leonardo Oliveira Carvalho ${ }^{2}$ \\ José Alves Dantas ${ }^{3}$ \\ Otávio Ribeiro de Medeiros ${ }^{4}$
}

\section{RESUMO}

Considerada a relevância da informação contábil aliada ao processo de auditoria, este estudo tem por objetivo verificar se o relatório de auditoria com opinião modificada influencia o retorno do preço das ações e a percepção de risco, e, adicionalmente, verificar se a ênfase provoca reação similar. Foram realizados testes de modelos de regressão multivariada que consideraram relatórios e cotações de 231 empresas/ação entre 2010 e 2017. Os resultados não apontaram significância estatística entre a opinião modificada e a variação do valor de mercado, mas revelaram que a opinião modificada afeta a percepção de risco dos investidores, comportamento similar na existência do parágrafo de ênfase onde os testes estatísticos apresentaram resultados inconclusivos em relação ao preço e significância para o aumento da volatilidade.

Palavras-chave: Relatório de auditoria, Opinião Modificada, Parágrafo de ênfase, Preço da Ação; Percepção de Risco.

\section{ABSTRACT}

Considering the relevance of the accounting information allied to the audit process, this study aims to verify if the audit report with modified opinion influences the stock price return and the perception of risk, and additionally verify if the emphasis causes similar reaction. We performed tests of multivariate regression models that considered reports and quotations of 231 companies / shares between 2010 and 2017. The results did not indicate statistical significance between the modified opinion and the market value chance, but revealed that the modified opinion affects investors'

\footnotetext{
${ }^{1}$ Bacharel em Ciências Contábeis pela Universidade de Brasília (UnB); E-mail: dl.carvalho@outlook.com

${ }^{2}$ Bacharel em Ciências Contábeis pela Universidade de Brasília (UnB); E-mail: leonardoc96@gmail.com

${ }^{3}$ Doutor em Ciências Contábeis pela Universidade de Brasília (UnB); Professor do Programa de Pós-Graduação em

Ciências Contábeis da Universidade de Brasília (UnB); E-mail: josealvesdantas@unb.br

${ }^{4}$ Doutor em Economia pela University of Southampton (SU), UK; Professor do Programa de Pós-Graduação em

Administração da Universidade de Brasília; E-mail: otavio@unb.br
} 
perception of risk, similar behavior in the existence of the emphasis paragraph where the statistical tests presented inconclusive results in relation to the price and significance for the increase of volatility.

Keywords: Audit Report, Modified Opinion, Emphasis Paragraph, Share Price; Perception of Risk.

\section{RESUMEN}

Considerado la relevancia de la información contable aliada al proceso de auditoría, este estudio tiene por objetivo verificar si el informe de auditoría con opinión modificada influye en el retorno del precio de las acciones y la percepción de riesgo, y, adicionalmente, verificar si el énfasis provoca reacción similar. Se realizaron pruebas de modelos de regresión multivariada que consideraron informes y cotizaciones de 231 empresas / acción entre 2010 y 2017. Los resultados no apuntar significancia estadística entre la opinión modificada y el cambio del valor de mercado, pero revelaron que la opinión modificada afecta la percepción de riesgo de los inversores, comportamiento similar en la existencia del párrafo de énfasis donde las pruebas estadística presentaron resultados inconclusos en relación al precio y significancia para el aumento de la volatilidad.

Palabras clave: Informe de auditoría, Opinión modificada, Párrafo de énfasis, Precio de la acción; Percepción de riesgo.

\section{INTRODUÇÃO}

A contabilidade é considerada uma ferramenta capaz de reduzir os problemas causados pela assimetria de informação (Bushman, \& Smith, 2001) através da veiculação de relatórios contábeis fidedignos, capazes de evidenciar a real situação econômico-financeira das entidades e mediar o conflito de agência (Chung, Judge, \& Li, 2015).

Isso pressupõe a existência de mecanismos que garantam que a divulgação realizada pela empresa traduza, com fidedignidade, os eventos e transações econômicas realizados e a sua real situação financeira e patrimonial. Daí a importância do processo de auditoria, que exerce o papel de reduzir assimetrias e assegurar a credibilidade às demonstrações financeiras, elementos fundamentais para um bom funcionamento do mercado de capitais (Dantas, \& Medeiros, 2015), pois para isso é necessário que os agentes envolvidos reúnam o máximo de informações possíveis para realizar a melhor escolha.

Ao cumprir a função de promover confiabilidade para os demonstrativos financeiros, a auditoria faz com que o mercado crie expectativas em relação ao processo de realização dos trabalhos dos auditores independentes, notadamente quanto à capacidade de detectar quaisquer anormalidades.

Sobre a utilidade das informações financeiras, diversos estudos, desde Beaver (1968) e Ball e Brown (1968), têm comprovado a relevância da divulgação das demonstrações financeiras nas decisões de investidores. Notadamente quanto ao papel da auditoria, Al-Thuneibat, Khamees e AlFayoumi (2007) ressaltam o consenso que existe na literatura contábil sobre a importância e relevância, tanto das informações financeiras divulgadas quanto do processo de auditoria, para a tomada de decisões dos usuários, e destacam que se não houver reação do mercado ao trabalho realizado pelo auditor, então o processo de auditoria passa a ser questionado.

Apesar dessa premissa teórica, estudos a respeito do impacto do relatório da auditoria no preço das ações das companhias ainda registra resultados inconclusivos. No âmbito internacional, por exemplo, Lee e Lee (2010) concluíram que a qualidade da auditoria afeta a relevância dos rendimentos e o valor das ações, ressaltando que os retornos eram maiores em empresas auditadas por big four, e Robu e Robu (2015) identificaram que a opinião modificada e a auditoria realizada por big four influenciam o retorno das ações. No Brasil, porém, Arruda, Sousa, Pena, Paulo e Paulo (2012) e Sobral (2014) identificaram que o tipo de relatório de auditoria não alterou o preço das ações e Nunes (2009) constatou que a percepção quanto ao risco e ao desempenho da empresa não se altera 
na existência de opinião modificada.

Nesse contexto, considerando que a literatura apresenta evidências ainda inconclusivas e contraditórias quanto aos impactos da opinião dos auditores independentes nas decisões dos investidores, o presente estudo se propõe a responder à seguinte questão de pesquisa: a opinião modificada no relatório de auditoria influencia o valor de mercado das ações de companhias brasileiras ou na percepção de risco dos investidores, no período seguinte?

O objetivo deste estudo, portanto, é verificar se o relatório de auditoria com opinião modificada influencia o preço das ações - por consequência, o valor de mercado das companhias - e na percepção de risco, representada pela volatilidade do retorno das ações. Adicionalmente, é investigado se a existência do parágrafo de ênfase no relatório da auditoria pode exercer o mesmo impacto no mercado de capitais, apesar de não caracterizar, necessariamente, associado a problemas de distorções nas demonstrações financeiras.

Como destacado, apesar de existirem estudos sobre o tema, esses apresentam resultados ainda inconsistentes entre si, principalmente na esfera nacional, o que justifica a necessidade de estudos acadêmicos com esse enfoque, principalmente se for considerado que o relatório de auditoria tem o potencial de fornecer informações relevantes, complementarmente às demonstrações financeiras, aos investidores. Assim, este trabalho procurou utilizar uma perspectiva de impacto no preço das ações e percepção de risco que não foi explorada pelos trabalhos citados, avaliando se um relatório com opinião modificada divulgado no exercício corrente, referente ao exercício anterior, é capaz de impactar a formação de preços desse período até a divulgação de novas informações - diferente dos estudos de evento clássicos, que avaliam o impacto de novas informações no momento em que elas ocorrem, com, no máximo, algum período de dias para ser analisado no mercado de capitais.

Para o alcance desse propósito, foram realizados testes por meio da estimação de modelos econométricos, utilizando informações obtidas dos relatórios de auditoria, das demonstrações financeiras anuais e dados sobre preços das ações de companhias não financeiras listadas na Brasil Bolsa Balcão (B3), entre 2010 e 2017.

Além dessa parte introdutória, que contextualiza o tema e define seus propósitos, este estudo contempla: a discussão sobre a relevância e o uso das informações contábeis pelos agentes do mercado de capitais, o papel da auditoria na divulgação financeira e o impacto do seu relatório no mercado de capitais (Seção 2); a definição dos procedimentos metodológicos aplicados para a realização dos testes empíricos (Seção 3); a análise dos resultados obtidos com os testes; (Seção 4); e as conclusões do estudo, com o cotejamento entre as premissas teóricas e as evidências empíricas (Seção 5).

\section{REFERENCIAL TEÓRICO}

A apresentação do referencial teórico está dividida em três partes: a descrição da importância da informação contábil para o funcionamento do mercado de capitais; a discussão sobre a relevância do papel da auditoria na divulgação financeira; e o relato sobre os estudos relacionados ao tema, incluindo a definição das hipóteses de pesquisa.

\subsection{A Informação Contábil e o Mercado de Capitais}

Informação é elemento fundamental para proporcionar eficiência ao mercado de capitais. Isso porque o alto volume de negociações, a magnitude dos montantes investidos e a diversidade de oportunidades de investimentos são fatores que dependem da confiança do investidor naqueles que administram as companhias, e transmitir informações confiáveis sobre a capacidade de geração de valor, sobre a evolução das operações de uma entidade e sobre as principais decisões tomadas pelos gestores é o que possibilita a esses investidores tomarem suas decisões de comprar, vender ou manter títulos mobiliários.

Os estudos positivistas sobre decisões financeiras estão ligados à denominada Teoria Moderna 
de Finanças, e expõem de forma explícita e tácita a necessidade de existirem informações fidedignas sobre o negócio, as quais serão inputs no processo de tomada de decisões. Esses estudos são constituídos de modelos financeiros e de precificação de ativos propostos a partir da década de 1950, com Markowitz (1952), Modigliani e Miller (1958), Willian Sharpe (1964), Ross, Westerfield e Jaffe (2010), dentre outros que contribuíram para o entendimento do mercado de capitais que conhecemos atualmente.

Quando Modigliani e Miller (1958) assumiram que o valor de uma empresa é determinado pela capacidade de geração de fluxos de caixa dos seus ativos, ou seja, por uma consequência intrínseca da qualidade de seus ativos, depreende-se que a melhor maneira de se projetar seus fluxos de caixa futuros é conhecendo as informações sobre esses ativos, como: capacidade produção, estimativas de desgastes, outros gastos envolvidos na operação, e quando possível, um histórico para avaliar o comportamento ao longo do tempo. Isso reforça a ideia de que manter uma sistemática de troca de informações é fundamental para qualquer projeto de investimento e em qualquer etapa.

Nessa linha de raciocínio, a informação contábil funciona como ferramenta capaz de reduzir os efeitos da assimetria de informação (Bushman, \& Smith, 2001), via veiculação de relatórios contábeis fidedignos, capazes de reduzir tal assimetria ao evidenciar a real situação econômicofinanceira e mediar o conflito de agência (Chung, Judge, \& Li, 2015).

Beaver (1968) sustenta a ideia de que um relatório financeiro de uma empresa possui conteúdo informacional se conduzir a alguma mudança na avaliação do investidor quanto à distribuição de probabilidades dos retornos futuros (ou preços), de tal forma que haja uma mudança no valor de equilíbrio do preço de mercado corrente. A partir do consenso teórico de que a contabilidade influencia na tomada de decisões dos usuários, pesquisas como as de Beaver (1968) e Ball e Brown (1968), que usaram a metodologia do estudo do evento para verificar se há associação entre as informações contidas nos lucros com os retornos das ações, trouxeram a abordagem empírica para a contabilidade, evidenciando o potencial informativo dos demonstrativos financeiros.

No Brasil, pode ser citado, entre outros, Bernardo (2001), que fez uma análise empírica sobre como o mercado reage à divulgação dos relatórios contábeis. Ela examinou como os investidores que atuam no mercado brasileiro de capitais reagem às divulgações trimestrais de resultado, observando o comportamento do preço de 32 empresas em datas próximas da divulgação dos demonstrativos trimestrais entre 1995 e 2001, totalizando 584 eventos. Seus achados demonstraram que a divulgação desses demonstrativos transmite informação relevante para os investidores, que reagem de maneira a afetar o preço das ações, ao interpretarem as notícias que surgem a todo momento como boas, neutras ou más.

Constatada a relevância da informação e o impacto que a contabilidade pode exercer no ambiente de negócios, há de se investigar qual é a reação do mercado em relação à peça fundamental que pode proporcionar confiabilidade e credibilidade, aos demonstrativos, que é o relatório de auditoria.

\subsection{O Papel da Auditoria na Divulgação Financeira}

A auditoria definida como o processo sistemático de obtenção e avaliação objetiva de evidências relacionadas a afirmações a respeito de ações e eventos econômicos, para aferir a correspondência e critérios estabelecidos e a comunicação dos resultados a usuários interessados (Auditing Concepts Committee, 1972), traz consigo uma clara noção do seu papel no mercado de capitais. Isso porque a função de coletar evidências suficientes para confirmar que as demonstrações apresentadas estão adequadas é o que leva confiabilidade ao investidor.

Damascena, Firmino e Paulo (2011) afirmam que a auditoria desempenha um importante papel na economia, no desenvolvimento de uma empresa e seus negócios, no governo e na prestação de informações para usuários internos e externos. Esse entendimento é coerente com o propósito da auditoria, exposto na NBC TA 200, que é aumentar o grau de confiança nas demonstrações financeiras por parte dos usuários, de modo que a expressão de sua opinião sobre tais relatórios visa 
reduzir a assimetria informacional existente entre os administradores e os demais usuários. Portanto, a existência da auditoria independente se relaciona à credibilidade, confiança e comparabilidade das informações divulgadas entre as diversas entidades que compõem o mercado (Dutra, Alberton, \& Van Bellen, 2007).

Segundo Dantas e Medeiros (2015), a confiabilidade das informações financeiras se configura como condição primordial para a eficiência do mercado de capitais. Portanto, a opinião da auditoria independente, ao propiciar a validação da veracidade e confiabilidade das informações contábeis apresentadas pelas companhias, também viabiliza o desenvolvimento do mercado de capitais. Assim, o relatório que consolida os trabalhos realizados pelo auditor independente torna-se peça importante da informação divulgada pelas empresas, podendo exercer influência significativa na tomada de decisões do investidor (Al-Thuneibat et al, 2007).

Ao influenciar na decisão dos investidores, o processo de auditoria independente passa a ser visto como peça capaz de fornecer informações para os investidores, desmistificando o entendimento de alguns investidores de que a auditoria seria apenas mais um exercício burocrático que a entidade deve manter por convenção. Desse modo, o papel da auditoria fica definido no âmbito do mercado de capitais, cumprindo sua função de verificar a conformidade das práticas contábeis e podendo fornecer informações relevantes complementarmente às demonstrações financeiras aos investidores.

\subsection{O Impacto do Relatório de Auditoria no Mercado de Capitais}

A importância atribuída ao processo de auditoria para o mercado de capitais só pôde ser notada depois de marcos históricos no âmbito contábil e de finanças, que expuseram as necessidades do processo, seja pelo crescimento das empresas, o aumento do número de sociedades abertas, a utilização de capital de terceiros, seja pelo estabelecimento de subsidiárias de multinacionais, como aponta o Instituto dos Auditores Independentes do Brasil - Ibracon (2006). E assim como os acontecimentos trouxeram à tona o surgimento de uma profissão, também vieram consigo o questionamento de diversos pesquisadores sobre a relevância efetiva do seu trabalho para o mercado de capitais.

Beaver (1968), Ball e Brown (1968) são nomes pioneiros que buscaram verificar a relevância da informação contábil em uma época que ainda se discutia uma harmonização dos procedimentos contábeis que pudessem reduzir assimetrias de informação, fase marcada principalmente pela criação do Financial Accounting Standards Board (FASB) nos Estados Unidos da América (EUA).

Firth (1978) foi outro autor dessa época que abordou o trabalho da auditoria como objeto de estudo. $\mathrm{O}$ autor categorizou o conteúdo da opinião dos auditores nos relatórios divulgados no Reino Unido para aferir a influência que estes poderiam exercer nas decisões de investimentos, concluindo que a opinião divulgada pelos auditores transmite informação relevante aos investidores. Porém, apenas algumas modalidades de opinião são relevantes, onde o auditor destaca um setor específico da empresa. Contudo, não foi possível relacionar a opinião divulgada às ocorrências de retornos anormais.

Gómez-Guillmón (2003) buscaram avaliar se o relatório de auditoria possui utilidade para usuários como instituições de crédito e analistas de empresas de corretagem. Por meio de aplicação de questionários, concluíram que o relatório de auditoria é fundamental para concessão de crédito e que uma opinião modificada altera o montante a ser emprestado ou investido na entidade. Também verificaram que ressalvas referentes a erros de avaliação de ativos e incertezas quanto à continuidade são as mais relevantes, concluindo que a informação expressa na opinião do auditor tem impacto nas decisões de financiamento e de investimento.

O trabalho de Menon e Williams (2010) explorou uma amostra de 1.194 empresas submetidas à Securities and Exchange Commission (SEC), excetuando as American Depositary Receipts (ADRs), para verificar se a opinião modificada por conta do posicionamento do auditor em relação à continuidade das operações, o Going Concern Audit Report (GCAR), impacta negativamente o retorno das ações, entre 1995 e 2006. 
$\mathrm{O}$ andamento das pesquisas envolveu analisar um período de grandes mudanças na área de governança corporativa, fase moldada por esforços para evitar grandes escândalos empresariais, como os que aconteceram no Banco Barings em 1995, Enron, WorldCom, Parmalat e Siemens no início dos anos 2000, e pelas crescentes mudanças na área de tecnologia, que influenciaram o mundo dos negócios pela adaptação das formas como as empresas traçam suas estratégias de crescimento e consolidação no mercado.

Estes são eventos que ajudam a entender em que contexto o mercado pode ter passado a dar uma maior atenção ao trabalho do auditor, que tem o potencial de fornecer informações não levadas em consideração apenas nas demonstrações, como ressaltam Menon e Williams (2010), ao indicarem que o conteúdo do GCAR, que relata problemas sobre como a empresa vem se financiando, gera nova informação para os investidores, ao passo que um GCAR contendo assuntos sobre dificuldades nas operações e desempenhos ruins sucessivos no resultado, não. Isso porque se espera que o mercado já venha acompanhando tais aspectos pelos demonstrativos, como apontam os autores. Sendo assim, a conclusão que Menon e Williams (2010) foi a de que a opinião do auditor sobre a continuidade da empresa influencia as decisões dos investidores apenas quando são capazes de gerar informações que o mercado não pôde acompanhar/projetar (novas informações), em outras palavras, que o impacto nos retornos observados depende do conteúdo do GCAR.

Alguns estudos com propósito similar tiveram resultados que corroboram a afirmação de que a opinião do auditor gera informação relevante e influencia as decisões dos investidores, impactando o preço das ações, como Ianniello e Galloppo (2015), que examinaram a reação dos investidores à opinião dos auditores quanto a continuidade ou risco financeiro, na Itália, entre 2007 e 2010, utilizando a metodologia do estudo do evento e encontrando um impacto negativo nas ações quando a opinião era desfavorável. Robu e Robu (2015) também constataram que havia influência da opinião dos auditores nos retornos das ações, no mercado acionário da Romênia durante o ano de 2012, utilizando o método da regressão com análise de covariância. Lee e Lee (2010) também identificaram impacto da auditoria no valor das ações em Taiwan, ao utilizar a regressão múltipla em um período de 1996 a 2009, examinando se havia relação entre a qualidade do processo de auditoria e o valor das medidas contábeis.

No Brasil, Sobral (2014) e Souza e Nardi (2018) foram responsáveis por pesquisas nesse mesmo sentido, com uso de modelos estatísticos e períodos de análises diferentes, mas resultados inconclusivos, pela falta de significância dos parâmetros estatísticos. Sobral (2014) analisou empresas listadas na B3, no período de 2010 a 2012, com o uso do teste de hipóteses $t$-Sudent para verificar se haveria presença ou não de retornos anormais após a publicação do parecer com ressalva ou abstenção de opinião, não tendo encontrado significância estatística para concluir que esse tipo de relatório causa impacto no preço das ações. Souza e Nardi (2018) fizeram testes em todas as empresas de capital aberto brasileiras, no período de 2010 a 2014, tendo encontrado evidências fracas de que o relatório com ressalvas tem relação positiva com o retorno das ações, e o relatório com parágrafo de ênfase possui relação negativa com este, apesar de não haver significância estatística em nenhum dos testes aplicados.

Com base nesse contexto, foi formulada a seguinte hipótese de pesquisa, a ser testada empiricamente:

$\mathrm{H}_{1 \mathrm{~A}}$ : No mercado de capitais brasileiro, a emissão de relatório de auditoria com opinião modificada influencia negativamente o preço das ações das companhias não financeiras no período seguinte.

Pelo potencial informativo do conteúdo do relatório, buscou-se avaliar outra perspectiva referente à percepção de risco dos investidores. A premissa, nesse caso, é que se a asseguração do auditor sobre as demonstrações financeiras ajuda na criação de um ambiente de confiança e credibilidade, a opinião modificada teria um efeito contrário a respeito da entidade divulgadora, tendo 
em vista a incerteza quanto à sua efetiva situação econômico-financeira. A consequência seria o aumento da percepção de risco dos investidores sobre a entidade, o que se refletiria no aumento da volatilidade do retorno das ações.

Para Balilini e Maciel (2017), a volatilidade é uma variável-chave na alocação e no apreçamento de ativos, em decisões de investimento e na análise de risco, representando um indicador de segurança e confiabilidade do preço das ações cotadas das companhias. Portanto, infere-se que o relatório com opinião modificada tende a impactar a percepção de risco por parte dos investidores, pois esse tipo de opinião indica que há incerteza relevante quanto aos dados econômico-financeiros divulgados pela entidade, e, consequentemente, gerando uma reação negativa pelo mercado dado pelo aumento da percepção de risco do mercado quanto ao futuro da entidade e aumentado a volatilidade das ações das empresas que obtiveram esse tipo de relatório. Isso dá suporte à seguinte hipótese de pesquisa, a ser testada empiricamente:

$\mathrm{H}_{1 \mathrm{~B}}$ :No mercado de capitais brasileiro, a emissão de relatório de auditoria com opinião modificada aumenta a volatilidade do retorno das ações das companhias não financeiras no período seguinte.

Buscando ampliar e complementar a pesquisa, explora-se uma outra hipótese relacionada ao conteúdo do relatório de auditoria, considerando o seu caráter informativo. A ênfase em algum assunto é exclusivamente uma questão de julgamento do auditor, que geralmente considera para a sua emissão as transações significativas com partes relacionadas, eventos subsequentes importantes que envolvam a venda de segmento relevante de uma empresa, riscos e incertezas associadas a contingências ou estimativas significantes, como explica Johnstone, Gramling e Rittenberg (2014). Como os assuntos geralmente abordados nesse tipo de parágrafo (importante ressaltar que não foram considerados os conteúdos dos parágrafos de "outros assuntos", apenas de "ênfase") trazem informações sobre acontecimentos que fogem da normalidade, é possível que o mercado reaja negativamente à sua existência, mesmo que isso não represente uma modificação de opinião. Assim, são formuladas hipóteses similares às hipóteses $\mathrm{H}_{1 \mathrm{~A}}$ e $\mathrm{H}_{1 \mathrm{~B}}$, mas substituindo a opinião modificada pelo parágrafo de ênfase, ou seja:

$\mathrm{H}_{2 \mathrm{~A}}$ : No mercado de capitais brasileiro, a emissão de relatório de auditoria com parágrafo de ênfase influencia negativamente o preço das ações das companhias não financeiras, no período seguinte.

$\mathrm{H}_{2 \mathrm{~B}}$ : No mercado de capitais brasileiro, a emissão de relatório de auditoria com parágrafo de ênfase aumenta a volatilidade do retorno das ações das companhias não financeiras, no período seguinte.

\section{PROCEDER METODOLÓGICO}

A descrição dos aspectos metodológicos empregados no trabalho compreende: a especificação dos modelos utilizados para a realização dos testes empíricos relativos ao impacto no preço e na volatilidade dos retornos; a definição da amostra utilizada; e a previsão dos procedimentos adotados na estimação dos modelos, de forma a assegurar a robustez dos achados empíricos.

\subsection{Modelo Especificado para Testar Impacto no Preço}

Para testar as hipóteses de pesquisa, que avaliam o impacto do relatório de auditoria com opinião modificada $\left(H_{1 A}\right)$ ou com parágrafo de ênfase $\left(H_{2 A}\right)$ no preço das ações, será utilizado, como referência, modelo inspirado em Ohlson (1995) e Collins et al. (1997).

Esses modelos originais relacionam o valor de mercado de uma companhia com suas informações contábeis, considerando como premissa a hipótese de eficiência do mercado em relação às novas informações recebidas pelos acionistas, sendo recorrente sua utilização para avaliar os efeitos de informações contábeis no preço das ações, como, por exemplo, Cupertino e Lustosa (2006), 
que analisaram a aplicabilidade do modelo de Ohlson (1995) para o mercado de capitais, concluindo pela possibilidade de extensões ao modelo e uma série de contribuições na literatura acadêmica sobre mercado de capitais. Cioffi (2009) também se inspirou nesse modelo para testar o efeito de sinalização dos dividendos no valor das empresas e na projeção de analistas, constatando uma influência da política de distribuição de dividendos no valor de mercado e uma melhor previsibilidade dos analistas para empresas com menor assimetria na informação.

De se ressaltar, porém, que a especificação do modelo (3.1), utilizado no presente estudo, não pode ser entendido como uma replicação literal dos modelos inspiradores, tendo em vista adaptações promovidas tanto na incorporação de variáveis de interesse para os propósitos do estudo, quanto na forma de mensuração das variáveis. Primeiro, como o objeto do presente trabalho trata o relatório de auditoria como peça informacional importante para o mercado, foram inseridas duas variáveis adicionais com a finalidade de testar se relatórios de auditoria com opinião modificada ou parágrafos de ênfase são capazes de influenciar no preço das ações de companhias brasileiras. A avaliação dos efeitos do lucro é feita com base no lucro líquido, seguindo Collins et al. (1997), e não no lucro anormal, como em Ohlson (1995). Adicionalmente, para lidar com o problema da não estacionariedade dos dados, que ocorre com séries temporais que utilizam o modelo de Ohlson (1995), identificado por estudos como os de Qi, Wu e Xiang (2000), foram utilizadas as variações entre o ano analisado $(\mathrm{t})$ e o anterior ( $\mathrm{t}-1)$ das variáveis que compõem o modelo, ficando representado da seguinte maneira:

$$
\Delta V M E A_{i, t}=\beta_{0}+\beta_{1} \Delta P L A_{i, t}+\beta_{2} \Delta L L A_{i, t}+\beta_{3} M O D_{i, t-1}+\beta_{4} E N F_{i, t-1}+\varepsilon_{i, t}
$$

Sendo:

$\triangle V M E A_{i, t}$ : Variação do valor de mercado por ação da companhia i no período;

$\triangle P L A_{i, t}:$ Variação do patrimônio líquido por ação da companhia i no período;

$\Delta L L A_{i, t}$ : Variação do lucro líquido por ação da companhia i no período;

$M O D_{i, t-1}$ : Variável dummy que assume valor 1 se a empresa i, no período t-1, teve relatório com modificação de opinião do auditor e 0 , caso contrário;

$E N F_{i, t-1}$ : Variável dummy que assume valor 1 se a empresa i, no período t-1, teve relatório com ênfase do auditor e 0 , caso contrário;

$\varepsilon_{i, t}$ : Termo de erro da regressão $\sim \mathrm{N}\left(0, \sigma^{2}\right)$.

Dessas variáveis, espera-se que haja relação positiva entre o retorno do valor de mercado, representado pela diferença dos preços das ações de um ano para o outro ( $\triangle V M E A$ ), o patrimônio líquido $(\triangle P L A)$ e lucro líquido $(\triangle L L A)$, enquanto para as variáveis de interesse do estudo relatório de auditoria com opinião modificada $(M O D)$ e com parágrafo de ênfase $(E N F)$, a relação esperada é negativa, representando um impacto negativo no valor de mercado da entidade, que é observado no período seguinte à divulgação do relatório.

\subsection{Modelo Especificado para Testar Impacto na Volatilidade}

Para testar as hipóteses de pesquisas que avaliam o impacto do relatório de auditoria com opinião modificada $\left(H_{1 B}\right)$ ou com parágrafo de ênfase $\left(H_{2 B}\right)$ na percepção de risco dos investidores quanto as ações das companhias brasileiras não financeiras, foi desenvolvido o modelo (3.2), contemplando como variáveis explicativas da volatilidade das ações não apenas as variáveis de interesse, mas também variáveis de controle definidas com base na literatura prévia.

$$
\begin{aligned}
V O L_{i, t}=\beta_{0}+ & \beta_{1} M O D_{i, t-1}+\beta_{2} E N F_{i, t-1}+\beta_{3} B 4_{i, t-1}+\beta_{4} T A M_{i, t}+\beta_{5} R O E_{i, t} \\
& +\beta_{6} A L A V_{i, t}+\beta_{7} G O V_{i, t}+\varepsilon_{i, t}
\end{aligned}
$$

Sendo:

$V O L_{i, t}$ : representa a volatilidade do retorno das ações da empresa i, no período t, calculado pelo 
desvio padrão anual dos retornos diários das empresas. Os retornos diários foram calculados mediante $R_{i t}=L N\left(P_{t} / P_{t-1}\right)$, em que P é o preço de fechamento da ação.

$M O D_{i, t-1}$ : variável dummy que assume valor 1 se a empresa $\mathrm{i}$, no período $\mathrm{t}-1$, teve o relatório com modificação de opinião do auditor e 0 , caso contrário.

$E N F_{i, t-1}$ : variável dummy que assume valor 1 se a empresa i, no período t-1, teve o relatório com ênfase do auditor e 0 , caso contrário.

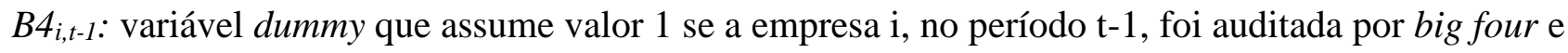
0 , caso contrário.

$T A M_{i, t}$ : refere-se ao tamanho da empresa i, no período t, dado pelo logaritmo natural do Ativo Total. $R O E_{i, t}$ : representa o retorno sobre o patrimônio líquido da empresa $\mathrm{i}$, no período $\mathrm{t}$, calculada pela divisão do Lucro Líquido pela média do Patrimônio Líquido dos dois últimos períodos.

$A L A V_{i, t}$ : representa o grau de alavancagem/endividamento da empresa i, no período $t$, calculado pela divisão do Passivo Total pelo Ativo Total.

$G O V_{i, t}$ : variável dummy que assume valor 1 se a empresa i, no período t, está listada nos Níveis de Governança Corporativa da B3 e 0 , caso contrário.

$\varepsilon_{i, t}$ : Termo de erro da regressão $\sim \mathrm{N}\left(0, \sigma^{2}\right)$.

No modelo em questão, as variáveis $M O D$ e $E N F$ são as variáveis de interesse para se concluir sobre as hipóteses de pesquisa $\mathrm{H}_{1 \mathrm{~B}}$ e $\mathrm{H}_{2 \mathrm{~B}}$. Com base nas fundamentações expostas no tópico 2.3, o relatório com modificação de opinião tende a alterar a percepção de risco do investidor, esperandose, portanto, uma associação positiva de $M O D$ com a volatilidade das ações ( $V O L)$. O parágrafo de ênfase, por apresentar uma informação relevante ao investidor, também tende a impactar na volatilidade das ações, esperando-se uma correlação positiva da variável ENF com o indicador de risco analisado.

Adicionalmente às variáveis de interesse, a construção segue Bushee e Noe (2000), que recomendam a utilização de variáveis de controle, pois fatores relacionados às especificidades das empresas tendem a impactar a volatilidade das ações. Portanto, foram adicionadas as variáveis de controle, correspondentes a um grupo de índices que evidenciam os aspectos gerais da situação econômico-financeira da empresa, entre outras variáveis.

DeAngelo (1981) argumenta que a qualidade da auditoria está positivamente relacionada com o tamanho firma de auditoria, pois elas estão mais bem capacitadas para identificar problemas nas demonstrações e são mais independentes para relatar os seus achados. Portanto, presume-se uma expectativa positiva vista pelo mercado, refletindo em uma maior confiança e menor volatilidade do preço das ações, sendo adicionada a variável $B 4$ que indica que o relatório é emitido por big four, em que, espera-se uma associação negativa com a volatilidade das ações.

O efeito tamanho, originalmente documentado por Banz (1981), consiste na evidência empírica de que ações de empresas pequenas apresentam maior retorno médio do que as de maior porte. A relação entre risco e retorno explica que, as pequenas empresas ao possuírem maiores retornos, são também as mais arriscadas, de modo que as empresas maiores, ao serem mais constantes e seguras, apresentam menor risco. Nesse contexto, foi incorporada a variável TAM relativa ao tamanho da empresa, esperando-se associação negativa com a volatilidade.

Ross, Westerfield e Jaffe (2010) argumentam que o investidor racional escolhe uma carteira de investimentos com o maior retorno esperado e menor desvio padrão, buscando maximizar os seus lucros mediante a diminuição do risco. Com base nisso, adicionou-se variável de controle $R O E$ representando uma medida de desempenho da entidade referente a sua rentabilidade. Portanto, associa-se que empresas mais rentáveis contêm menor risco, presumindo assim, uma relação negativa com a volatilidade.

Christie (1982) defende que um dos fatores que pode afetar a variação dos preços de uma ação é o grau de alavancagem financeira da empresa. O efeito alavancagem determina que, se o preço de uma ação cai (sobe), a alavancagem financeira se eleva (diminui), pois altera a proporção de capital de terceiros em relação ao capital próprio, de modo que tal movimento torna a ação mais arriscada, 
incrementando a volatilidade dos retornos subsequentes. Portanto é adicionada a variável independente $A L A V$, representando o endividamento da entidade, em que se uma associação positiva com a volatilidade das ações.

Para Huang, Chan, Huang e Chang (2011), melhores práticas de governança corporativa ajudam a melhorar os mecanismos de monitoramento das firmas, de modo a reduzir os problemas de agência e a probabilidade de prejudicar os interesses do investidor. Silveira, Barros e Famá (2003) também destaca que boas práticas de governança afetam o valor das organizações. Isso justifica a adição da variável de controle $G O V$, indicando se empresa está listada em algum dos Níveis de Governança Corporativa da B3. Infere-se que uma melhor governança corporativa por parte da companhia ajuda a aumentar a confiança do investidor, implicando na estabilidade do preço da ação. Portanto, espera-se uma relação negativa com a volatilidade do retorno.

\subsection{Amostra e Dados}

A realização do estudo envolveu a coleta de dados econômico-financeiros anuais e histórico de cotações diárias dos preços das ações ajustada pela distribuição de proventos de 371 empresas não financeiras listadas na B3, entre 2010 e 2017.

Ao contrário de um estudo de evento típico, em que se procura mensurar os efeitos de um evento em uma janela de tempo estreita - geralmente representada por um número reduzido de dias antes e após o evento - o presente estudo avalia o impacto da opinião modificada do auditor sobre o grau de confiança e credibilidade em que os investidores tomam decisões, o que deve se refletir de forma mais perene. A premissa considerada é que o ambiente de incerteza gerado por uma opinião modificada de auditoria sobre as demonstrações financeiras de determinado exercício influencia a formação de preços e a percepção de risco em relação à companhia auditada durante o período seguinte e até que essa situação de falta de clareza e confiança seja diluída com a proximidade da nova divulgação. Por essa razão, serão consideradas informações anualizadas sobre o comportamento do preço das ações - data de referência 31/12, contemplando um espaço temporal prévio à divulgação das demonstrações, de forma equivalente ao que ocorre nos estudos de evento.

Tabela 1: Seleção da amostra

\begin{tabular}{lcc}
\hline \multicolumn{1}{c}{ Descrição } & Quantidade & Percentual \\
\hline Total de empresas pesquisadas & 371 & $100,00 \%$ \\
(-) Empresas com baixa negociação na bolsa ${ }^{1}$ & 66 & $17,78 \%$ \\
(-) Empresas com PL negativo em algum exercício $t$ & 110 & $29,64 \%$ \\
= Total de empresas utilizadas nos testes & $\mathbf{1 9 5}$ & $\mathbf{5 2 , 5 6 \%}$ \\
Total de empresas/ação utilizadas nos testes & $\mathbf{2 3 1}$ & \\
Empresas listadas nos segmentos de Governança Corporativa & 126 & $64,50 \%$ \\
Empresas não listadas nos segmentos de Governança Corporativa & 69 & $35,50 \%$ \\
= Total de empresas utilizadas nos testes & $\mathbf{1 9 5}$ & $\mathbf{1 0 0 , 0 0 \%}$ \\
\hline
\end{tabular}

${ }^{1}$ Foram consideradas empresas com alta negociação na Bolsa aquelas com dias de movimentação igual ou superior a 126 dias, que é a metade dos dias úteis para negociação do mercado, em média.

${ }^{2}$ É a observação que relaciona o número de empresas aos tipos de ações mais líquidas, sendo que algumas das 195 empresas possuíam liquidez nos dois tipos de ação - ON e PN - resultando em 231 empresas/ação a ser utilizadas nos testes.

Os testes consideraram apenas empresas que possuíam dados relativos às demonstrações, relatórios de auditoria e o histórico de cotação dos preços no período de 2009 a 2017, excluindo-se as que tinham movimentação inferior a 126 dias de negociação, que é a metade dos dias úteis anuais de negociação no mercado, em média, e incluindo-se todas as empresas que apresentaram modificação de opinião, ainda que não possuíssem o nível de negociação das ações estabelecido. Também foram excluídas empresas que possuíam patrimônio líquido negativo, o que comprometeria a análise do impacto da opinião modificada do auditor no preço das ações, uma vez que esse tipo de informação por si só já impacta negativamente o preço de mercado das ações, como constatado por Bernardo (2001).

A análise abrangeu o preço de ações ordinárias e preferenciais, de acordo com o requisito de 
liquidez estabelecido. Assim, para as empresas que atendiam esse requisito de liquidez nas duas classes de ações (ON e PN), ambas foram consideradas para análise. Desse modo, do total de empresas que tiveram seus dados coletados, foi possível estabelecer um rol de 195 empresas, que resultaram em 231 empresas/ação. A Tabela 1 resume o tratamento dado a essas empresas.

\subsection{Métodos para Estimação dos Modelos}

Com o propósito de assegurar a robustez dos testes empíricos, os modelos (3.1) e (3.2) foram estimados, considerando os métodos: de regressão agrupada (pooled), que ignora os efeitos da heterogeneidade individual; e de dados em painel, com controle da heterogeneidade individual, com efeitos fixos seccionais, efeitos fixos no período e duplos efeitos fixos. O propósito é que essa combinação de testes funcione como uma espécie de análise de sensibilidade, ou seja, avaliar se os resultados são consistentes entre si, independentemente do método de estimação do modelo.

Preliminarmente à estimação do modelo, foi avaliado o risco de multicolinearidade, utilizando como referência a premissa sugerida por Gujarati (2006), de que a robustez dos coeficientes e dos erros padrões das regressões ficam comprometidos quando há correlação superior a 0,8 entre as variáveis independentes. No caso do risco de heterocedasticidade nos resíduos, esse é mitigado, incialmente, pela relativização das variáveis não dicotômicas, em função do número de ações. Adicionalmente, considerando as evidências preliminares de risco de autocorrelação nos resíduos, as estimações foram realizadas com o método SUR/PCSE (Seemingly Unrelated Regressions/Panel Corrected Standard Errors), que gera erros padrões robustos mesmo na presença de autocorrelação e heteroscedasticidade nos resíduos.

\section{RESULTADOS, ANÁLISES E DISCUSSÃO}

A primeira etapa dos testes consistiu em analisar os relatórios de auditoria sobre as demonstrações financeiras das 231 empresas/ação da amostra, considerando o período do ano de 2009 a 2016. Na Tabela 2 são consolidadas as estatísticas gerais desse mapeamento.

Tabela 2: Estatísticas gerais das empresas analisadas

\begin{tabular}{lcc}
\multicolumn{1}{c}{ Descrição } & Quantidade & Percentual \\
\hline Total de histórico de cotação por empresa (ON e PN) & 2.162 & $100,00 \%$ \\
Ações ordinárias & 1.407 & $65,07 \%$ \\
Ações preferenciais & 755 & $34,92 \%$ \\
\hline Total de relatórios de auditoria & 2.162 & $100,00 \%$ \\
Demonstrações auditadas por big four & 1.618 & $74,80 \%$ \\
Demonstrações de empresas com nível de governança & 1.395 & $64,50 \%$ \\
\hline Sem Ressalva & 2.063 & $95,42 \%$ \\
Com Ressalva & 88 & $4,07 \%$ \\
Abstenção de Opinião & 11 & $0,50 \%$ \\
Opinião Adversa & 0 & $0,00 \%$ \\
\hline Relatórios contendo parágrafo de ênfase & 1.129 & $52.20 \%$ \\
\hline
\end{tabular}

A combinação de empresa por tipo de ação se deu através do critério de exclusão daquelas de menor liquidez e pela inexistência de uma das classes em algumas companhias. Através dessas 231 empresas/ação, 2.162 dados de cotações de preços de ações em todo o período de análise foram utilizados nos testes, assim, 1.407 representa o número de ações ordinárias para o estudo, e 755 preferenciais.

Das empresas utilizadas nos testes, nota-se que $74,80 \%$ são auditadas por firmas Big Four, uma parcela significativa que comprova a predominância das maiores firmas de auditoria do mundo no mercado de capitais brasileiro. Além disso, boa parte das companhias analisadas são classificadas em algum dos seguimentos de governança da B3 - Bovespa Mais, Bovespa Mais Nível 2, Novo Mercado, Nível 2 ou Nível $1-64.50 \%$ das empresas.

Sobre os 2.162 relatórios de auditoria utilizados como uma das variáveis nos testes, $52.20 \%$ 
possuíam parágrafo de ênfase e 4,57\% (99 relatórios) registraram opinião modificada - ressalva ou abstenção de opinião. Mais de $95 \%$ dos relatórios de auditoria, portanto, são de opinião não modificada - sem ressalva.

\subsection{Estatísticas Descritivas}

A Tabela 3 apresenta as estatísticas descritivas das variáveis não dicotômicas dos modelos (3.1) e (3.2), contemplando os dados das empresas integrantes da amostra.

Tabela 3: Estatísticas descritivas das variáveis não dicotômicas dos modelos (3.1) e (3.2)

\begin{tabular}{cccccc}
\hline Variável & Média & Mediana & Máximo & Mínimo & Desvio Padrão \\
\hline $\boldsymbol{\Delta} \boldsymbol{V} \boldsymbol{M} \boldsymbol{A}$ & 26,1452 & 11,7000 & 923,7700 & 0,0000 & 63,0442 \\
$\boldsymbol{\Delta} \boldsymbol{P} \boldsymbol{A}$ & 18,5733 & 9,2352 & 698,9537 & 0,0004 & 39,9673 \\
$\boldsymbol{\Delta} \boldsymbol{L} \boldsymbol{A}$ & 1,3860 & 0,5807 & 382,2429 & $-44,9063$ & 11,1022 \\
$\boldsymbol{T} \boldsymbol{A} \boldsymbol{M}$ & 22,1651 & 22,1547 & 27,5258 & 16,0521 & 1,7848 \\
$\boldsymbol{R} \boldsymbol{O} \boldsymbol{E}$ & 0,2542 & 0,0849 & 139,4893 & $-2,8168$ & 3,9931 \\
$\boldsymbol{A} \boldsymbol{L} \boldsymbol{} \boldsymbol{V}$ & 0,5431 & 0,5578 & 0,9959 & 0,0000 & 0,2008 \\
\hline
\end{tabular}

Onde: $\triangle V M E A$ é a variação do valor de mercado por ação; $\triangle P L A$ é a variação do patrimônio líquido por ação; $\triangle L L A$ é a variação do lucro líquido por ação;; TAM refere-se ao tamanho da empresa; ROE: representa o retorno sobre o patrimônio líquido; $A L A V$ representa o grau de alavancagem/endividamento.

De acordo com a Tabela 3, destaca-se a variação do preço das ações ( $\triangle V M E A)$ com uma grande variabilidade, tendo como valor mínimo um preço por ação muito próximo do zero, comportamento similar à variação do patrimônio líquido por ação $(\triangle P L A)$. Alguns fatores podem explicar essa grande variabilidade, como a existência de empresas de setores muito diferentes na amostra e a presença de empresas que nos últimos anos estão em processo de recuperação judicial, explicando o valor mínimo muito próximo de zero.

Já para a variação do lucro líquido por ação ( $\triangle L L A)$, nota-se um desvio padrão menor que as outras duas variáveis. Isso indica que o desempenho das empresas pelo resultado líquido tem uma variabilidade menor que o valor de mercado por ação e o patrimônio líquido por ação, apesar da diversidade de setores na amostra.

A volatilidade $(V O L)$ anual média das ações das companhias brasileiras representa 3,74\%, representando o risco médio das ações das empresas. Verificou-se um grau de risco máximo de $54,43 \%$, e um desvio padrão de $4,34 \%$, o que evidencia as demais diferenças entre as empresas analisadas.

No caso das variáveis dummy, os dados apresentados, anteriormente, na Tabela 2 demonstram que: menos de $5 \%$ dos relatórios de auditoria examinados receberam opinião modificada (MOD); mais da metade dos relatórios contam com parágrafo de ênfase $(E N F)$; e cerca de $75 \%$ dos trabalhos de auditoria examinados foram realizados por big four (B4). Adicionalmente, cabe ressaltar que $65 \%$ das observações consideradas se referem a instituições que atendem às condições definidas nos níveis de governança corporativa da B3 (GOV).

\subsection{Impacto no Preço}

\subsubsection{Análise Univariada e Teste de Multicolinearidade}

De forma preliminar à estimação do modelo (3.1), foi elaborada a matriz de correlação entre as variáveis, conforme a Tabela 4, para se observar o comportamento pela análise univariada, que detalha as interações entre elas de forma distinta, além de prevenir do risco de multicolinearidade, ao observar se há alto grau de correlação entre os pares de regressores.

Pelo critério sugerido por Gujarati (2006), não há risco de multicolinearidade, tendo em vista que a correlação entre as variáveis independentes não foi maior que 0,8 , o que comprometeria a robustez dos coeficientes e dos erros padrões das regressões. 
Tabela 4: Matriz de correlação de Pearson entre os regressores do modelo (3.1)

\begin{tabular}{|c|c|c|c|c|c|}
\hline & DVMEA & $\Delta$ PLA & $\Delta$ LLA & MOD & ENF \\
\hline DVMEA & 1,0000 & & & & \\
\hline$\Delta \mathbf{P L A}$ & 0,1769 & 1,0000 & & & \\
\hline$\Delta \mathbf{L L A}$ & 0,0639 & 0,3155 & 1,0000 & & \\
\hline MOD & 0,0163 & 0,0000 & 0,0190 & 1,0000 & \\
\hline ENF & 0,0102 & 0,0291 & 0,0168 & 0,0093 & 1,0000 \\
\hline
\end{tabular}

Onde: $\triangle V M E A$ é a variação do valor de mercado por ação; $\triangle P L A$ é a variação do patrimônio líquido por ação; $\triangle L L A$ é a variação do lucro líquido por ação; $M O D$ representa a variável dummy que assume valor 1 se a empresa, teve relatório com modificação de opinião do auditor e 0, caso contrário; e ENF representa a variável dummy que assume valor 1 se a empresa teve relatório com ênfase do auditor e 0 , caso contrário.

Destacam-se as seguintes evidências na análise univariada, como o comportamento positivo entre a variável de interesse que representa a variação do valor de mercado das ações $(\triangle V M E A)$ e as variáveis independentes de variação do patrimônio líquido por ação $(\triangle P L A)$ e variação do lucro líquido por ação $(\angle L L A)$. Esse comportamento é um dos resultados esperados, pois o modelo (3.1) parte da premissa de que essas informações são fundamentais na formação do valor de mercado de uma entidade.

Para as variáveis de interesse $M O D$ e $E N F$, diferente do esperado pelas hipóteses formuladas, a análise univariada apresentou correlação positiva para ambas, apontando, preliminarmente, que essas duas variáveis não exercem influência significativa na formação do preço das ações das entidades analisadas.

\subsubsection{Estimação do Modelo (3.1)}

Para testar as hipóteses $\mathrm{H}_{1 \mathrm{~A}}$ e $\mathrm{H}_{1 \mathrm{~B}}$ foram realizadas estimações do modelo (3.1), com o uso de dados em painel. Para fins de análise de sensibilidade dos resultados, são promovidas estimações com os métodos de regressão agrupada (pooled), efeitos fixos seccionais, efeitos fixos temporais e duplos efeitos fixos. A Tabela 5 consolida os resultados encontrados.

Pelos dados contidos na Tabela 5, foi possível constatar a relação positiva e relevante das informações sobre o patrimônio líquido por ações $(\triangle P L A)$ e a variável dependente que representa o retorno do valor de mercado das ações $(\triangle V M E A)$. Isso confirma a teoria de que as informações contábeis sobre o PL influenciam no valor de mercado das ações, pois a composição do patrimônio líquido serve de referência para analistas estimarem valores, taxas de remuneração e resultados, como destaca Cupertino e Lustosa (2006).

Contudo, não foi constatada significância na relação das informações sobre o lucro/prejuízo líquido das empresas ( $\triangle L L A)$ e o valor de mercado das ações ( $\triangle V M E A)$. O que contraria o modelo teórico de Ohlson (1995) de que o mercado absorve informações de resultados esperados. Essa mesma constatação foi feita, por exemplo, em: Cioffi (2009), na pesquisa que relacionou a sinalização dos dividendos e a avaliação do valor das empresas; Grillo et al. (2016), ao investigarem os efeitos da utilização do conceito de valor justo para mensuração de elementos patrimoniais sobre a relevância das informações contábeis nas empresas brasileiras; e Guia e Dantas (2019), que também não identificou relevância significativa entre essas duas variáveis, no seu estudo sobre a relevância informacional dos ativos fiscais diferidos para os bancos brasileiros.

Para as variáveis de interesse, não foi encontrada significância estatística na relação entre a existência de opinião modificada $(M O D)$ e o retorno do valor de mercado das ações das empresas no exercício seguinte, o que evidencia a rejeição da hipótese $\mathrm{H}_{1 \mathrm{~A}}$, ou seja, não há relação estatisticamente relevante entre a opinião modificada e a variação do valor de mercado das empresas.

Esse resultado é o mesmo encontrado por Sobral (2014) e Souza e Nardi (2018), e traz à tona a inferência de diversos pesquisadores da área de que a informação contábil pode assumir uma posição complementar, não substituta, das informações que de fato têm um peso na formação de valor de mercado das ações. 
Tabela 5: Estimação do modelo (3.1) para avaliação do impacto do relatório de auditoria com opinião modificada e parágrafo de ênfase no preço das ações (valor de mercado)

\begin{tabular}{|c|c|c|c|c|}
\hline \multicolumn{5}{|c|}{ Modelo testado: $\Delta V M E A_{i, t}=\beta_{0}+\beta_{1} \Delta P L A_{i, t}+\beta_{2} \Delta L L A_{i, t}+\beta_{3} M O D_{i,(t-1)}+\beta_{4} E N F_{i,(t-1)}+\varepsilon_{\mathrm{i}, \mathrm{t}}$} \\
\hline & Pooled & $\begin{array}{c}\text { Efeitos Fixos no } \\
\text { Período }\end{array}$ & $\begin{array}{c}\text { Efeitos Fixos } \\
\text { Seccionais }\end{array}$ & Duplos Efeitos Fixos \\
\hline $\mathbf{C}$ & $\begin{array}{c}2,6595 \\
(0,1147)\end{array}$ & $\begin{array}{c}1,3714 \\
(0,4503)\end{array}$ & $\begin{array}{c}0,6426 \\
(0,7369)\end{array}$ & $\begin{array}{l}-2,2539 \\
(0,3071)\end{array}$ \\
\hline$\Delta P L A_{i, t-1}$ & $\begin{array}{c}0,3114 \\
(0,0000) \\
\quad * * *\end{array}$ & $\begin{array}{c}0,3833 \\
(0,0000) \\
* * *\end{array}$ & $\begin{array}{c}0,3120 \\
(0,0000) \\
* * *\end{array}$ & $\begin{array}{c}0,3805 \\
(0,0000) \\
* * *\end{array}$ \\
\hline$\Delta L L A_{i, t-1}$ & $\begin{array}{l}-0,0654 \\
(0,4666)\end{array}$ & $\begin{array}{l}-0,1380 \\
(0,1208)\end{array}$ & $\begin{array}{l}-0,0724 \\
(0,4217)\end{array}$ & $\begin{array}{l}-0,1442 \\
(0,1054)\end{array}$ \\
\hline$M O D_{i, t-1}$ & $\begin{array}{l}-2,8438 \\
(0,5609)\end{array}$ & $\begin{array}{c}3,1638 \\
(0,6202)\end{array}$ & $\begin{array}{l}-2,7676 \\
(0,5723)\end{array}$ & $\begin{array}{c}3,8448 \\
(0,5475)\end{array}$ \\
\hline$E N F_{i, t-1}$ & $\begin{array}{c}-5,7780 \\
(0,0079) \\
* * *\end{array}$ & $\begin{array}{c}-4,1920 \\
(0,0849) \\
*\end{array}$ & $\begin{array}{l}-2,4116 \\
(0,3632)\end{array}$ & $\begin{array}{c}1,8176 \\
(0,5703)\end{array}$ \\
\hline $\mathrm{N}^{\circ}$ empresas/ação: & 225 & 225 & 225 & 225 \\
\hline No observações: & 1541 & 1541 & 1541 & 1541 \\
\hline Período & $2010 / 2017$ & $2010 / 2017$ & $2010 / 2017$ & $2010 / 2017$ \\
\hline$R^{2}$ & 0,0238 & 0,2116 & 0,0313 & 0,2210 \\
\hline$R^{2}$ ajustado & 0,0213 & 0,0746 & 0,0243 & 0,0807 \\
\hline F Estatística & 9,4018 & 1,5447 & 4,5000 & 1,5754 \\
\hline F (p-valor) & $(0,0000)$ & $(0,0000)$ & $(0,0000)$ & $(0,0000)$ \\
\hline Durbin-Watson & 1,5827 & 1,9538 & 1,5848 & 1,9670 \\
\hline
\end{tabular}

Onde: $\triangle V M E A$ é a variação do valor de mercado por ação; $\triangle P L A$ é a variação do patrimônio líquido por ação; $\triangle L L A$ é a variação do lucro líquido por ação; $M O D$ representa a variável dummy que assume valor 1 se a empresa, teve relatório com modificação de opinião do auditor e 0, caso contrário; e $E N F$ representa a variável dummy que assume valor 1 se a empresa teve relatório com ênfase do auditor e 0 , caso contrário.

Nível de significância: *** 1\%;**5\%;*10\%. P-valores entre parênteses.

No caso dos testes envolvendo a variável independente que representa a existência do parágrafo de ênfase $(E N F)$ no relatório do auditor, foram identificados resultados inconclusivos. Foi constatada relação negativa e significante entre a divulgação de tal parágrafo e a variação do valor de mercado das ações $(\triangle V M E A)$ em duas estimações, enquanto para outras duas estimações não foi confirmada significância estatística. Esse resultado pode significar que o mercado fica em alerta quando há a existência do parágrafo de ênfase, interpretando-o como uma notícia desfavorável, apesar de não indicar, necessariamente, que a empresa possui problemas.

\subsection{Impacto na Volatilidade}

\subsubsection{Análise Univariada e Teste de Multicolinearidade}

Preliminarmente à estimação do modelo (3.2), foi elaborada matriz de correlação entre as variáveis independentes, para prevenir o risco de multicolinearidade e identificar se há alto grau de correlação entre pares de regressores.

Os resultados encontrados apontam uma relação positiva entre os relatórios com modificação de opinião $(M O D)$ e a volatilidade do preço das ações $(V O L)$, indicando um primeiro indicio de associação entre a emissão desses relatórios com a maior percepção de risco dos investidores em relação a essas empresas. Os parágrafos de ênfase $(E N F)$ também apresentaram associação positiva com a medida de risco, embora em menor escala que a modificação de opinião.

Quanto as variáveis de controle como as empresas que tiveram os relatórios emitidos por big four (B4) apresentaram uma associação negativa com a volatilidade das ações, indicando uma possível relação entre a maior reputação da firma e o menor grau de risco desse investimento. As 
variáveis referentes ao tamanho $(T A M)$ e retorno sobre o patrimônio líquido $(R O E)$ apresentaram correlação negativa com o indicador de risco das ações, podendo-se inferir que companhias maiores e mais rentáveis apresentam menor risco.

Tabela 6: Matriz de correlação de Pearson entre os regressores do modelo (3.2)

\begin{tabular}{|c|c|c|c|c|c|c|c|c|}
\hline & VOL & $M O D$ & $E N F$ & $B 4$ & TAM & $\begin{array}{l}R O E \\
\end{array}$ & $A L A V$ & GOV \\
\hline VOL & 1,0000 & & & & & & & \\
\hline$M O D$ & 0,2109 & 1,0000 & & & & & & \\
\hline$E N F$ & 0,0629 & 0,0643 & 1,0000 & & & & & \\
\hline B4 & $-0,2456$ & $-0,1846$ & 0,0431 & 1,0000 & & & & \\
\hline$T A M$ & $-0,1987$ & $-0,1234$ & 0,0511 & 0,3806 & 1,0000 & & & \\
\hline ROE & $-0,0155$ & $-0,0019$ & $-0,0240$ & 0,0199 & $-0,0955$ & 1,0000 & & \\
\hline$A L A V$ & 0,0195 & 0,1044 & 0,0408 & 0,0888 & 0,2890 & $-0,0223$ & 1,0000 & \\
\hline GOV & $-0,1460$ & $-0,1478$ & 0,0926 & 0,2479 & 0,2001 & 0,0037 & $-0,0244$ & 1,0000 \\
\hline
\end{tabular}

Onde: VOL representa a volatilidade do retorno das ações; $M O D$ representa a variável dummy que assume valor 1 se a empresa, teve relatório com modificação de opinião do auditor e 0, caso contrário; ENF representa a variável dummy que assume valor 1 se a empresa teve relatório com ênfase do auditor e 0 , caso contrário; $B 4$ é a variável dummy que assume valor 1 se a empresa foi auditada por big four e 0, caso contrário; TAM refere-se ao tamanho da empresa; ROE: representa o retorno sobre o patrimônio líquido; $A L A V$ representa o grau de alavancagem/endividamento; e $G O V$ é variável dummy que assume valor 1 se a empresa está listada nos Níveis de Governança Corporativa da B3 e 0, caso contrário.

A associação entre a alavancagem $(A L A V)$ e a volatilidade do retorno das ações foi positiva, indicando que empresas mais endividadas possuem maior risco. De maneira análoga, as companhias que participam de algum segmento de governança corporativa $(G O V)$ tiveram uma associação negativa com a medida de risco, inferindo-se que essas empresas são menos arriscadas, por transmitirem uma ideia de maior transparência e confiabilidade das informações divulgadas.

Utilizando a regra sugerida por Guajarati (2006), verifica-se que não há risco de multicolinearidade entre as variáveis, dado que a relação entre as mesmas não foi maior que 0,8 , que caracterizaria o alto risco de multicolineariedade.

\subsubsection{Estimação do Modelo (3.2)}

Para testar as hipóteses propostas na seção 2.3 foram realizadas estimações do modelo (3.2), com o uso de dados em painel. Para fins de análise de sensibilidade dos resultados, são promovidas estimações com os métodos pooled, efeitos fixos seccionais, efeitos fixos no período e duplos efeitos fixos, todas com o uso do método SUR/PCSE, que gera erros padrões robustos, mesmo na presença de autocorrelação e heteroscedasticidade nos resíduos. Os resultados são consolidados na Tabela 7.

Os resultados dos testes empíricos constatam que os relatórios de auditoria com modificação de opinião $(M O D)$ apresentam associação positiva e estatisticamente significante com a volatilidade do retorno das ações das companhias brasileiras $(V O L)$, no exercício seguinte em todas as estimações testadas. Isso significa que, a emissão de um relatório de auditoria com opinião modificada altera a percepção de risco dos investidores em relação à entidade, refletindo-se numa maior variabilidade dos preços de suas ações, isto é, maior volatilidade. Esses resultados corroboram as expectativas da hipótese $\mathrm{H}_{1 \mathrm{~B}}$ e são coerentes com as evidências encontradas por Ianniello e Galloppo (2015) e Robu e Robu (2015). Também se verificou que a presença de parágrafo de ênfase no relatório de auditoria $(E N F)$ possui relação positiva com a volatilidade do retorno das ações, sendo estatisticamente relevante em três das quatro estimações realizadas. Portanto, quando o auditor chama a atenção em seu relatório para um item das demonstrações financeiras que poderá afetar significativamente a sua posição patrimonial e financeira, o impacto é refletido na volatilidade das ações. Isso significa que a divulgação dessa informação altera a percepção de risco do investidor frente à empresa, embora isso não signifique modificação de opinião em relação ao que está sendo divulgado. Desse modo, a hipótese $\mathrm{H}_{2 \mathrm{~B}}$ é corroborada, dadas as evidências de que a ênfase do auditor é um dado significativo para tomada de decisões do usuário, traduzindo em maior volatilidade do retorno das ações. Tais resultados também confirmam as evidências encontradas por Menon e Williams (2010) e Souza e Nardi (2018). 
Tabela 7: Estimação do modelo (3.2) para identificação do impacto do relatório de auditoria com opinião modificada e parágrafo de ênfase na volatilidade do retorno das ações

\begin{tabular}{|c|c|c|c|c|}
\hline \multicolumn{5}{|c|}{$\begin{array}{c}\text { Modelo testado: } \\
\mathrm{VOL}_{\mathrm{i}, \mathrm{t}}=\beta_{0}+\beta_{1} \mathrm{MOD}_{\mathrm{i}, \mathrm{t}-1}+\beta_{2} \mathrm{ENF}_{\mathrm{i}, \mathrm{t}-1}+\beta_{3} \mathrm{~B} 4_{\mathrm{i}, \mathrm{t}-1}+\beta_{4} \mathrm{TAM}_{\mathrm{i}, \mathrm{t}}+\beta_{5} \mathrm{ROE}_{\mathrm{i}, \mathrm{t}}+\beta_{6} \mathrm{ALAV}_{\mathrm{i}, \mathrm{t}}+\beta_{7} \mathrm{GOV}_{\mathrm{i}, \mathrm{t}}+\varepsilon_{\mathrm{i}, \mathrm{t}}\end{array}$} \\
\hline & Pooled & $\begin{array}{l}\text { Efeitos Fixos no } \\
\text { Período }\end{array}$ & $\begin{array}{l}\text { Efeitos Fixos } \\
\text { Seccionais }\end{array}$ & Duplo Efeitos Fixos \\
\hline $\mathbf{C}$ & $\begin{array}{c}0,1174 \\
(0,0000) \\
* * *\end{array}$ & $\begin{array}{c}0,1216 \\
(0,0000) \\
* * *\end{array}$ & $\begin{array}{c}0,0337 \\
(0,2505)\end{array}$ & $\begin{array}{c}0,0869 \\
(0,0043) \\
* * *\end{array}$ \\
\hline MOD $_{\mathrm{i}, t-1}$ & $\begin{array}{c}0,0367 \\
(0,0002) \\
* * *\end{array}$ & $\begin{array}{c}0,0368 \\
(0,0002) \\
* * *\end{array}$ & $\begin{array}{c}0,0186 \\
(0,0172) \\
* *\end{array}$ & $\begin{array}{c}0,0195 \\
(0,0118) \\
* *\end{array}$ \\
\hline ENFi,t-1 & $\begin{array}{c}0,0064 \\
(0,0223) \\
* *\end{array}$ & $\begin{array}{c}0,0114 \\
(0,0020) \\
* * *\end{array}$ & $\begin{array}{c}0,0033 \\
(0,1104)\end{array}$ & $\begin{array}{c}0,0052 \\
(0,0415) \\
* *\end{array}$ \\
\hline $\mathbf{B} 4_{\mathrm{i}, \mathrm{t}-\mathbf{1}}$ & $\begin{array}{c}-0,0166 \\
(0,0000) \\
* * *\end{array}$ & $\begin{array}{c}-0,0161 \\
(0,0000) \\
* * *\end{array}$ & $\begin{array}{l}-0,0047 \\
(0,1890)\end{array}$ & $\begin{array}{l}-0,0053 \\
(0,1145)\end{array}$ \\
\hline $\mathbf{T A M}_{\mathrm{i}, \mathrm{t}}$ & $\begin{array}{c}-0,0034 \\
(0,0000) \\
* * *\end{array}$ & $\begin{array}{c}-0,0036 \\
(0,0000) \\
* * *\end{array}$ & $\begin{array}{l}-0,0007 \\
(0,5950)\end{array}$ & $\begin{array}{c}-0,0030 \\
(0,0379) \\
* *\end{array}$ \\
\hline $\mathbf{R O E}_{\mathrm{i}, \mathrm{t}}$ & $\begin{array}{c}-0,0002 \\
(0,0017) \\
* * *\end{array}$ & $\begin{array}{c}-0,0003 \\
(0,0009) \\
* * * *\end{array}$ & $\begin{array}{l}-0,0000 \\
(0,9693)\end{array}$ & $\begin{array}{l}-0,0001 \\
(0,2396)\end{array}$ \\
\hline $\mathbf{A L A V}_{\mathrm{i}, \mathrm{t}}$ & $\begin{array}{c}0,0131 \\
(0,0088) \\
* * *\end{array}$ & $\begin{array}{c}0,0105 \\
(0,0350) \\
* *\end{array}$ & $\begin{array}{c}0,0397 \\
(0,0000) \\
* * *\end{array}$ & $\begin{array}{c}0,0342 \\
(0,0004) \\
* * *\end{array}$ \\
\hline $\mathbf{G O V}_{\mathrm{i}, \mathrm{t}}$ & $\begin{array}{c}-0,0050 \\
(0,0135) \\
* *\end{array}$ & $\begin{array}{c}-0,0057 \\
(0,0063) \\
* * *\end{array}$ & & \\
\hline $\mathrm{N}^{\circ}$ empresas/ação: & 231 & 231 & 231 & 231 \\
\hline $\mathrm{N}^{\circ}$ observações: & 1636 & 1636 & 1636 & 1636 \\
\hline Período & 2010/2017 & 2010/2017 & 2010/2017 & 2010/2017 \\
\hline $\mathrm{R}^{2}$ & 0,1048 & 0,1159 & 0,6078 & 0,6120 \\
\hline $\mathrm{R}^{2}$ ajustado & 0,1010 & 0,1083 & 0,5406 & 0,5433 \\
\hline F Estatística & 27,2542 & 15,1878 & 9,0532 & 8,9069 \\
\hline $\mathrm{F}$ (p-valor) & 0,0000 & 0,0000 & 0,0000 & 0,0000 \\
\hline Durbin-Watson & 0,7119 & 0,7178 & 1,5806 & 1,5849 \\
\hline
\end{tabular}

Onde: VOL representa a volatilidade do retorno das ações; MOD representa a variável dummy que assume valor 1 se a empresa, teve relatório com modificação de opinião do auditor e 0 , caso contrário; ENF representa a variável dummy que assume valor 1 se a empresa teve relatório com ênfase do auditor e 0, caso contrário; B4 é a variável dummy que assume valor 1 se a empresa foi auditada por big four e 0 , caso contrário; TAM refere-se ao tamanho da empresa; ROE: representa o retorno sobre o patrimônio líquido; ALAV representa o grau de alavancagem/endividamento; e GOV é variável dummy que assume valor 1 se a empresa está listada nos Níveis de Governança Corporativa da B3 e 0, caso contrário.

Nível de significância: *** 1\%; ** 5\%; *10\%. P-valores entre parênteses

A variável de controle referente às companhias auditadas pelas maiores firmas de auditoria (B4) tiveram relação negativa e estatisticamente relevante com o indicador de risco das ações, sinalizando que o investidor atribui maior confiança às demonstrações financeiras auditadas por big four. Isso indica que a maior reputação da auditoria também reflete no mercado de capitais, corroborando com os resultados encontrados por Robu e Robu (2015) e Lee e Lee (2010).

As outras variáveis de controle também obtiveram associações esperadas com a volatilidade das ações. Conforme se verifica na tabela, o tamanho $(T A M)$ e retorno sobre o patrimônio líquido $(R O E)$ tiveram relação negativa e estatisticamente relevante com a volatilidade, demonstrando que empresas maiores e mais rentáveis costumam ser mais confiáveis, na percepção dos investidores, e, portanto, menor volatilidade no comportamento do preço de suas ações. Já a alavancagem (ALAV) teve relação positiva e estatisticamente significante com a volatilidade, pois empresas mais endividadas são mais arriscadas. Por fim, as empresas que participam de algum tipo de segmento de 
governança corporativa $(G O V)$ registraram relação negativa e estatisticamente significante com a volatilidade, revelando que as entidades enquadradas nessa categoria buscam garantir confiabilidade aos acionistas, possuindo um grau menor de risco associado aos investimentos. Em síntese, considerando os propósitos do presente estudo, verifica-se que tanto relatórios desfavoráveis (relatório de auditoria com modificação de opinião e relatório com parágrafo de ênfase) como informações contábeis impactam na percepção de risco do investidor, refletindo-se no mercado de capitais brasileiro e evidenciando a relevância de tais informações e o processamento eficiente dessas pelo mercado, conforme verificado nos estudos de Bernardo (2001).

\section{CONCLUSÕES}

O presente trabalho teve como objetivo verificar se o relatório de auditoria com opinião modificada influencia a formação do preço das ações, isto é, no retorno do valor de mercado, e na percepção de risco, representada pela volatilidade dos retornos. Adicionalmente, foi observado se a existência do parágrafo de ênfase pode exercer impacto no mercado de capitais, apesar de não representar, necessariamente, problemas com a divulgação financeira.

Os resultados encontrados não evidenciaram o impacto na formação do valor de mercado das ações, culminando na rejeição da hipótese $\mathrm{H}_{1 \text { A }}$. Por outro lado, ao avaliar o impacto na percepção de risco dos investidores, os testes demonstraram que o relatório da auditoria com modificação de opinião apresenta associação positiva e estatisticamente significante com a volatilidade do retorno das ações das companhias brasileiras, corroborando a hipótese $\mathrm{H}_{1 \mathrm{~B}}$. Isso significa que, apesar da emissão de opinião modificada não reduzir, de forma consistente, o valor de mercado das companhias, os agentes de mercado reagem através do aumento da percepção de risco em relação às ações da entidade. Esses resultados evidenciam que a emissão de relatório de auditoria com opinião modificada pode aumentar as incertezas em relação à situação econômico-financeira da entidade, se traduzindo em maior volatilidade no retorno das ações. Essa maior volatilidade ajuda a explicar, a não constatação de redução estatisticamente relevante no valor das ações das empresas que receberam opinião modificada sobre suas demonstrações - em ambiente de maior volatilidade é mais difícil a consolidação de um movimento de redução de preço.

Em relação à presença de parágrafo de ênfase do relatório de auditoria, as evidências empíricas não são conclusivas quanto à redução do preço das ações e demonstram associação positiva com a volatilidade do retorno das ações. Esses resultados são equivalentes, em essência, aos apurados em relação à modificação de opinião, refutando $\mathrm{H}_{2 \mathrm{~A}}$. e corroborando $\mathrm{H}_{2 \mathrm{~B}}$, respectivamente. Isso pode indicar que o parágrafo de ênfase, apesar de não necessariamente indicar problemas com a entidade, desperta o interesse de investidores que procuram extrair alguma informação para projetar os possíveis rumos da empresa, e daí tomar suas decisões.

A combinação desses resultados reforça a percepção de que, mais do que influenciar em determinada direção o comportamento do preço das ações da entidade divulgadora, o conteúdo do relatório de auditoria é importante para transmitir confiabilidade e segurança aos investidores premissas fundamentais para o funcionamento dos mercados. Assim, a modificação de opinião - e até a presença de parágrafos de ênfase - pode tornar os agentes de mercado menos confiantes na tomada de decisão, influenciando a volatilidade dos retornos sobre as ações das entidades divulgadores.

As evidências empíricas deste estudo contribuem para o desenvolvimento da literatura sobre o tema, em particular sobre como os agentes de mercado reagem ao conteúdo do relatório dos auditores, principalmente se considerarmos a incipiência de pesquisas a respeito no Brasil. Suportam a principal premissa teórica sobre o papel desempenhado pelos auditores, que é contribuir para um ambiente caracterizado pela confiança e credibilidade, com a redução da assimetria informacional condição fundamental para o funcionamento do mercado de capitais.

Por outro lado, há um espaço amplo de aspectos não contemplados no presente estudo e que 
são relevantes para um maior conhecimento sobre os efeitos do conteúdo do relatório dos auditores no comportamento dos agentes de mercado, como: a avaliação sobre a distinção de impactos em função do tipo de modificação de opinião, do tipo de assunto abordado, do valor real ou estimado da distorção, do segmento econômico no qual a entidade opera; o exame da reação do mercado aos principais assuntos de auditoria, que foram incorporados a partir de 2016; o impacto do relatório dos auditores no nível de liquidez das ações; a análise dos efeitos da reincidência de modificação sobre as demonstrações financeiras da mesma entidade.

O estudo tem como limitação o fato da amostra se restringir às empresas não financeiras e listadas na B3, não podendo suas evidências serem estendidas a outras amostras ou grupos de entidades. Também é importante ressaltar que a amostra utilizada contempla apenas as empresas que participam ativamente nas negociações do mercado financeiro brasileiro.

\section{REFERÊNCIAS}

Al-Thuneibat, A. A., Khamees, B. A., \& Al-Fayoumi, N. A. (2007). The effect of qualified auditors' opinions on share prices: evidence from Jordan. Managerial Auditing Journal, 23(1), 84-101.

American Accounting Association. (1972). Report of the committee on basic auditing concepts. The Accounting Review, 47(Supplement), 15-74.

Arruda, M. P., de Sousa, R. A. M., Pena, T. J. S., de Melo, I. I. S. L., \& Paulo, E. (2012). Repercussão do anúncio dos pareceres de auditoria no preço das ações das companhias abertas brasileiras. Revista da Faculdade de Administração e Economia, 4(1), 230-250.

Ball, R., \& Brown, P. (1968). An empirical evaluation of accounting income numbers. Journal of accounting research, 159-178.

Banz, R. W. (1981). The relationship between return and market value of common stocks. Journal of Financial Economics, 9(1), 3-18.

Beaver, W. H. (1968). The information content of annual earnings announcements. Journal of Accounting Research, 6(Issue Empirical Research in Accounting Selected Studies), 67-92.

Bernardo, H. P. (2001). Avaliação empírica do efeito dos anúncios trimestrais de resultado sobre o valor das ações no mercado brasileiro de capitais (Dissertação de Mestrado). Universidade de São Paulo, Programa de Pós-Graduação em Controladoria e Contabilidade, São Paulo.

Bushee, B. J., \& Noe, C. F. (2000). Corporate disclosure practices, institutional investors, and stock return volatility. Journal of Accounting Research, 171-202.

Bushman, R. M., \& Smith, A. J. (2001). Financial accounting information and corporate governance. Journal of Accounting and Economics, 32(1-3), 237-333.

Christie, A. A. (1982). The stochastic behavior of common stock variances: Value, leverage and interest rate effects. Journal of Financial Economics, 10(4), 407-432.

Chung, H., Judge, W. Q., \& Li, Y. H. (2015). Voluntary disclosure, excess executive compensation, and firm value. Journal of Corporate Finance, 32, 64-90.

Cioffi, P. L. M. (2009). O Modelo de Ohlson Aplicado ao Mercado de Capitais Brasileiro para Verificar a Sinalização dos Dividendos no Valor e na Avaliação das Empresas Abertas. Pontifícia Universidade Católica, Programa de Pós-Graduação em Administração, São Paulo.

Collins, D. W., Maydew, E. L., \& Weiss, I. S. (1997). Changes in the value-relevance of earnings and book values over the past forty years. Journal of Accounting and Economics, 24(1), 39-67.

Cupertino, C. M., \& Lustosa, P. R. B. (2006). O modelo Ohlson de avaliação de empresas: tutorial para utilização. Contabilidade Vista \& Revista, 17(1), 47-68.

Damascena, L. G., Firmino, J. E., \& Paulo, E. (2011). Estudo sobre os Pareceres de Auditoria: Análise dos parágrafos de ênfase e ressalvas constantes nas demonstrações contábeis das companhias listadas na Bovespa. Contabilidade Vista \& Revista, 22(2), 125-154.

Dantas, J. A., \& de Medeiros, O. R. (2015). Determinantes de qualidade da auditoria independente em bancos. Revista Contabilidade \& Finanças, 26(67), 43-56.

DeAngelo, L. E. (1981). Auditor size and audit quality. Journal of Accounting and Economics, 3(3), 183199.

Duréndez Gómez-Guillamón, A. (2003). The usefulness of the audit report in investment and financing decisions. Managerial Auditing Journal, 18(6/7), 549-559. 
Dutra, M. H.; Alberton, L.; Van Bellen, H. M. A análise de conteúdo aplicada aos parágrafos de ênfase e de informação relevante dos pareceres da auditoria independente emitidos para as empresas do setor elétrico. In Anais, $31^{\circ}$ Encontro da ANPAD. Rio de Janeiro, ANPAD.

Firth, M. (1978). Qualified audit reports: their impact on investment decisions. The Accounting Review, 53(3), 642.-650, 1978.

Grillo, F. F., Lachini, T. C., Baioco, V. G., Reina, D., \& Sarlo Neto, A. (2016). Value Relevance: análise dos efeitos da avaliação a valor justo. ConTexto, 16(32), 94-109.

Guia, L. D., \& Dantas, J. A. (2020). Value relevance dos ativos fiscais diferidos na indústria bancária brasileira. Revista Contabilidade \& Finanças, 31(82), 33-49.

Gujarati, D. N. (2006). Econometria básica. 4 ed. Rio de Janeiro: Elsevier-Campus.

Huang, H. H., Chan, M. L., Huang, I. H., \& Chang, C. H. (2011). Stock price volatility and overreaction in a political crisis: The effects of corporate governance and performance. Pacific-Basin Finance Journal, 19(1), 1-20.

Ianniello, G., \& Galloppo, G. (2015). Stock market reaction to auditor opinions-Italian evidence. Managerial Auditing Journal, 30(6/7), 610-632.

Instituto dos Auditores Independentes do Brasil. (2006). Auditoria: Registros de uma profissão. São Paulo: Ibracon.

Johnstone, K., Gramling, A., \& Rittenberg, L. E. (2014). Auditing: a risk-based approach to conducting a quality audit. Cengage learning.

Lee, H. L., \& Lee, H. (2013). Do Big 4 audit firms improve the value relevance of earnings and equity? Managerial Auditing Journal, 28(7), 628-646.

Maciel, L. S., \& Ballini, R. (2017). Modelagem e previsão do valor em risco com modelos de volatilidade baseada em variação: evidências empíricas. Revista Contabilidade \& Finanças, 28(75), 361-376.

Markowitz, H. (1952). Portfolio selection. The Journal of Finance, 7(1), 77-91.

Menon, K., \& Williams, D. D. (2010). Investor reaction to going concern audit reports. The Accounting Review, 85(6), 2075-2105.

Modigliani, F., \& Miller, M. H. (1959). The cost of capital, corporation finance, and the theory of investment: Reply. The American Economic Review, 49(4), 655-669.

Nunes, D. M. S. (2009). Uma análise da influência do parecer dos auditores independentes com ressalvas em decisões de usuários das informações contábeis. Universidade de Brasília, Programa de Pós-Graduação em Ciências Contábeis, Brasília.

Ohlson, J. A. (1995). Earnings, book values, and dividends in equity valuation. Contemporary Accounting Research, 11(2), 661-687.

Qi, D. D., Wu, Y. W., \& Xiang, B. (2000). Stationarity and cointegration tests of the Ohlson model. Journal of Accounting, Auditing \& Finance, 15(2), 141-160.

Robu, M. A., \& Robu, I. B. (2015). The influence of the audit report on the relevance of accounting information reported by listed Romanian companies. Procedia Economics and Finance, 20, 562-570.

Ross, S. A.; Westerfield, R. W.; Jaffe, J. F.(2010). Corporate Finance. 9.ed. New York: McGraw Hill.

Sharpe, W. F. (1964). Capital asset prices: A theory of market equilibrium under conditions of risk. The Journal of Finance, 19(3), 425-442.

Silveira, A. M., Barros, L. A., \& Famá, R. (2003). Estrutura de governança e desempenho financeiro nas companhias abertas brasileiras: um estudo empírico. Caderno de Pesquisas em Administração, 10(1), 57-71.

Sobral, P. R. B. (2014). Impacto do parecer da auditoria com ressalva ou abstenção de opinião no preço das ações das companhias listadas na BM\&FBOVESPA (Monografia de Especialização). Universidade Federal do Paraná, Departamento de Contabilidade e Finanças, Curitiba.

Souza, B. F., \& Nardi, P. C. C. (2018). Influência da Opinião do Auditor no Retorno das Ações das Empresas Brasileiras de Capital Aberto. Revista Contabilidade, Gestão e Governança, 21(2), 250270. 